\title{
Turning back the harmful red tide
}

\section{Harmful algal blooms are a serious and increasing problem in marine waters, yet scientists and funding agencies have been slow to investigate possible control strategies.}

\section{Donald M. Anderson}

Each holiday season I await the visit of one relative with trepidation. Years ago he asked whether I had "stopped that red tide problem yet?" - a simple question from one convinced that science solves problems directed to a so-called expert on the destructive and often visible 'blooms' of phytoplankton that kill fish, make shellfish poisonous and cause numerous other problems in coastal waters. I explained that we did not understand the causative organisms, their ecology or oceanography well enough to propose control strategies, but that one day we would.

Although temporarily satisfied with my argument, each year thereafter my brotherin-law repeated the question, and each year my answer was the same. Whatever progress had been made, there were new questions to be addressed. Eventually, he concluded that I did not want to solve the problem, as that would end my research programme. He is wrong, of course, but the explanation is far more complex than he would think, and is in part the subject of this article.

Throughout history, blooms of microscopic algae have had a major impact on fish, birds, mammals and other organisms in the marine food web. These 'red tides' (now termed harmful algal blooms) take many forms and have many effects. Some toxic algae kill wild and farmed fish. Others produce potent neurotoxins that accumulate in filter-feeding shellfish and poison human consumers. Algal toxins can alter the structure and function of marine ecosystems, affecting fecundity and survival at all levels.

Even non-toxic algae can be harmful when they accumulate in sufficient numbers — sometimes millions of cells per litre - to discolour the water, shade submerged vegetation, disrupt food-web dynamics and cause oxygen depletion. At the other extreme, toxic algae can be a tiny fraction of the total phytoplankton population and still be dangerous. Diarrhetic shellfish poisoning, for example, has been reported with Dinophysis concentrations of a few hundred cells per litre.

The scale and timing of harmful algal blooms is highly variable. Some are localized, occurring in bays or estuaries; others are massive, covering thousands of square kilometres. Some occur at the same time and place each year; others strike in random fashion. Some last a few weeks, others years.

Harmful algal blooms are not new phenomena. Red tides are recorded in the Bible and in the fossil record. What is new is the recent proliferation of harmful blooms ${ }^{1}$. There is debate about the nature and causes of this expansion. Some call it a global epidemic linked to pollution and human changes to coastal ecosystems ${ }^{2}$. Others argue that the expansion is in part an artefact reflecting increases in the number of scientists, advances in toxin detection, and the proliferation of aquaculture and other activities requiring product monitoring ${ }^{1,3}$.

One thing is certain - there is a growing global problem at a time when human reliance on coastal zones for food, recreation and commerce is rapidly expanding. Nevertheless, there is practically no exploration of direct control of marine blooms - attempting to kill or remove the cells or reduce their toxicity. At an international conference on harmful algae held in Vigo, Spain, in June, only one contribution of more than 400 abstracts from 58 countries addressed direct control of marine blooms. Imagine the difference if the conference had been on agricultural pests or on algal blooms in fresh water, where control efforts are common.

Research efforts on mitigation strategies such as shellfish-monitoring and aquaculture site management are critically important, but they treat the symptoms without attacking the problem. Government officials and the public want to know what is being done, or what can be done, in terms of direct intervention. So far, we have little to offer other than tentative predictions of bloom reductions decades from now if nutrient loadings are reduced.

I believe that some harmful algal blooms can be controlled or managed, not 20 years from now, but in the near future, economically and without disastrous environmental consequences. This belief may brand me as a heretic among my colleagues, some of whom fear that the ocean will be further despoiled by inept human attempts to manipulate ecosystems we do not understand.

At the heart of this negativism is a conviction that mankind does not possess the skills, knowledge or right to manipulate the marine environment on any significant scale. We are, however, already doing exactly that. By polluting coastal waters, we change the abundance and relative amounts of critical plant nutrients, which in turn alters the species composition of planktonic ecosystems. Indeed, this may be why there is an increasing number of harmful algal blooms. We are harvesting fish and shellfish at an alarming rate, removing components of the food-web with little knowledge of how such enormous manipulations affect other levels.

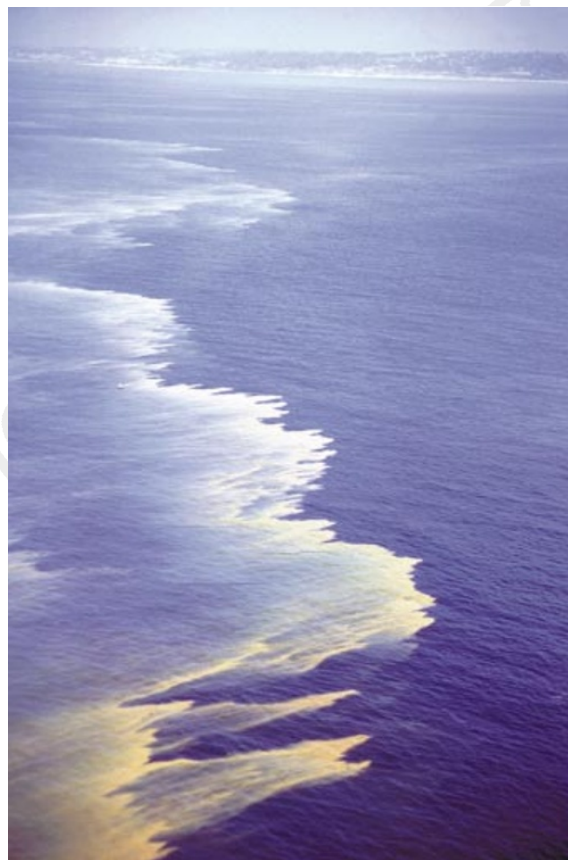

Some red tides, such as this non-toxic bloom of Noctiluca off California, cover huge areas, making it difficult to foresee environmentally benign bloom-control strategies (see also http://www.redtide.whoi.edu/hab/).

To replace dwindling natural fishery resources, we are turning coastal waters and wetlands into marine farms at an extraordinary rate. Whether by fish or shrimp farms (which have been likened to small cities with respect to their production of organic matter as pollutants), or by shellfish or seaweed culture (which strip plankton and nutrients from the water), we are altering near-shore waters significantly. Coastal ecosystems are no longer pristine and will not revert to their 'natural' state without intervention.

\section{From land to ocean}

Distrust of our ability to control pests and diseases seems to be based more on pessimism than on fact. When biological control is discussed, for example, some are quick to point out failures such as the introduction of the mongoose to oceanic islands or the giant toad to Australia ${ }^{4}$. Obscured by these failures is a multitude of successes in terrestrial biocontrol of weeds and pests ${ }^{4}$. Overall, 165 insect pests and 35 weed species have been controlled. Less than 2 per cent of the introductions became pests themselves, and many of those were 'generalist' predators an approach that is no longer practised.

Other examples of terrestrial management strategies include integrated pest 
management, which combines biological control with chemical agents such as narrow-spectrum pesticides, and ecologically based pest management, which attempts to work with ecosystem processes in the management effort ${ }^{5}$. The conceptual framework for pest management on land is far advanced, and should be a valuable resource in planning the management of marine systems. Instead it is largely ignored and misunderstood.

Extrapolation from land to the ocean will admittedly be difficult, as marine and terrestrial systems differ in scale, complexity and dynamics ${ }^{6}$. Application of a control agent to a single crop on a parcel of land is certainly simpler than the marine equivalent, where water motions will change the distribution and abundance of target organisms and applied control agents. Control of an outbreak at one site may have no effect on blooms in later years at the same location ${ }^{6}$. Another difference is that the community of organisms in marine ecosystems is more diverse and complex than that in single-crop agricultural systems.

Yet another factor that has stalled progress is the tendency to generalize that all blooms are massive. One colleague argues that blooms, like tornadoes or hurricanes, can be tracked and their movements predicted, but never controlled. He may be right about the larger blooms, but many are small or localized, either permanently or during key stages of development. For example, destructive brown tides in Texas or New York are thought to begin in certain bays and then to spread to adjacent waters. A widespread coastal bloom might be localized and accessible at an earlier stage.

Another constraint is that most countries have no official policy for funding marine pest management. In the United States, the Department of Agriculture puts extensive resources into terrestrial pest management. By contrast, the equivalent agency responsible for the oceans, the National Oceanic and Atmospheric Administration, has no marine pest-control programmes. Lacking strong leadership or targeted funding programmes at the national level, scientists opt for research on fundamental ecological or oceanographic issues less likely to be rejected during peer-review.

\section{Control options}

But there are signs of change in at least some parts of the world. South Korea has established a harmful algal bloom engineering division at its National Fisheries Research and Development Institute. And Australia's Commonwealth Scientific and Industrial Research Organization has established a Centre for Research on Introduced Marine Pests, which plans a proactive approach to marine pest management consistent with the country's aggressive reliance on terres- trial biological control. It is not clear whether this new programme will support research on control of harmful algal blooms.

During a red tide in Florida 40 years ago, copper sulphate was applied to 10,000 acres of shoreline using crop-dusting planes ${ }^{7}$. The treatment was initially effective, but blooms reappeared within weeks. Copper was deemed too expensive and non-specific to be used other than for short-term, small-scale bloom control. In another study, 4,700 chemicals were screened for use against Florida's red-tide alga, but none was sufficiently potent in natural sea water without also having adverse effects on other organisms.

Since then, chemical control options have received little attention, and no significant bloom-control research has been undertaken in the United States. Japan, China and Korea are exploring control strategies because they 'farm' their coastal waters heavily through aquaculture. Faced with significant economic losses from red tides, Japan initiated a broad evaluation of bloomcontrol strategies in the mid-1970s. Much of our knowledge of possible approaches comes from this outdated but useful series of studies ${ }^{9}$, which continues to this day, but at a much-reduced level of effort.

One promising strategy treats blooms with flocculents such as clay that scavenge particles, including algal cells, from sea water and carry them to bottom sediments. Removal efficiencies of 95-99 per cent have been achieved in laboratory cultures using clay, and small-scale field trials near fish farms have also been successful, though expensive ${ }^{8}$. New clays that are an order of magnitude more efficient in cell removal have been tested in China; this capacity can be further increased using coagulants such as polyhydroxy aluminium chloride?

Applications in China have been limited to tests in shrimp aquaculture ponds but, in 1996, 60,000 tons of clay were used in Korea to control a Cochlodinium red tide threatening near-shore fish farms. About $100 \mathrm{~km}^{2}$ were treated over several weeks, and nearly 100,000 tonnes of clay are now stockpiled in anticipation of the next bloom.

Clay is a non-toxic, naturally occurring material. Fish and bottom-dwelling organisms are unaffected by extremely high clay loadings near pottery industries ${ }^{10}$. The prospects look good, but considerable research is needed before large-scale field applications can be attempted. Obvious concerns are the fate and effects of sedimented cells and toxins on bottom-dwelling animals, and the collateral mortality of cooccurring planktonic organisms.

Biological control of harmful algal blooms also has potential. Zooplankton that graze on bloom species have been proposed as control agents ${ }^{8}$ but remain untested because of the impracticality of growing and maintaining predators in sufficient quantity.
Viruses are abundant in marine systems, replicate rapidly and tend to be hostspecific, suggesting that a single algal species could be targeted ${ }^{11}$. Parasites ${ }^{12}$ also have potential to control algal bloom species, but specificity is largely unknown. There are numerous examples of bacterial strains ${ }^{13}$ exhibiting strong and specific algicidal activity, although no field applications have yet been attempted.

\section{Prognosis for the future}

I have mentioned only a few of many potential control strategies. We must cautiously explore all possible approaches, but this requires funding at the scale needed to provide data to support informed decisions and override our preconceptions. We also need to establish guidelines for acceptable marine treatments.

In one sense, the problems we face with harmful algal blooms are similar to those encountered in agriculture or medicine, fields in which control of pests and diseases is a practical reality. The marine environment is admittedly different, but our hesitancy reflects a de facto acceptance that the problems are insurmountable. I believe they are not, and that we can make progress if new resources are made available and if we learn from the mistakes and successes of more than 100 years of experience controlling terrestrial pests.

There is a thin line to walk here - to argue that we have been too cautious and that success is possible, without promising more than we can deliver, unrealistically raising the expectations of the public and politicians. I also worry that funds needed for ecological studies might be diverted to control. I see the risks, but I also see the chance that this article may initiate a debate that will ultimately direct scientific thought and resources towards practical solutions. My brother-inlaw would no doubt approve.

Donald M. Anderson is at the Woods Hole

Oceanographic Institution, Woods Hole,

Massachusetts 02543, USA.

e-mail:danderson@whoi.edu

1. Anderson, D. M. in Red Tides: Biology, Environmental Science and Toxicology (eds Okaichi, T., Anderson, D. M. \& Nemoto, T.) 11-16 (Elsevier, New York, 1989).

2. Smayda, T. J. in Novel Phytoplankton Blooms (eds Cosper, E. M. et al.) 213-228 (Springer, New York, 1989).

3. Hallegraeff, G. M. Phycologia 32, 79-99 (1993).

4. Greathead, D. J. in Biological Control: Benefits and Risks (eds Hokkanen, H. M. T. \& Lynch, J. M.) (Cambridge Univ. Press, 1995).

5. Ecologically based Pest Management: New Solutions for a New Century (National Academy, Washington, DC, 1996).

6. Lafferty, K. D. \& Kuris, A. M. Ecology 77, 1989-2000 (1996).

7. Rounsefell, G. A. \& Evans, J. E. US Fish Wildlife Serv. Spec. Sci. Rep. 270 (1958)

8. Shirota, A. Int. J. Aquacult. Fisheries Technol. 1, 195 (1989).

9. Yu, Z., Zou, J. Z. \& Ma, X. Oceanologia et Limnologia Sinica 25, 226-232 (1994).

10. Howell, B. R. \& Shelton, R. G. J. J. Mar. Biol. Ass. UK 50, 593-607 (1970)

11. Milligan, K. L. D. \& Cosper, E. M. Science 266, 805 (1994). 12. Taylor, F. J. R. J. Fish. Res. Board. Can. 25, 2241-2245 (1968). 13. Yoshinaga, I., Kawai, T. \& Ishida, Y. Fish. Sci. 63, 94 (1997). 